Document downloaded from:

http://hdl.handle.net/10251/81575

This paper must be cited as:

Villalba Sanchis, I.; Insa Franco, R.; Salvador Zuriaga, P.; Martínez Fernández, P. (2017). Methodology for evaluating thermal track buckling in dual gauge tracks with continuous welded rail. Proceedings of the Institution of Mechanical Engineers, Part F: Journal of Rail and Rapid Transit. 231(3):269-279. doi:10.1177/0954409715626957.

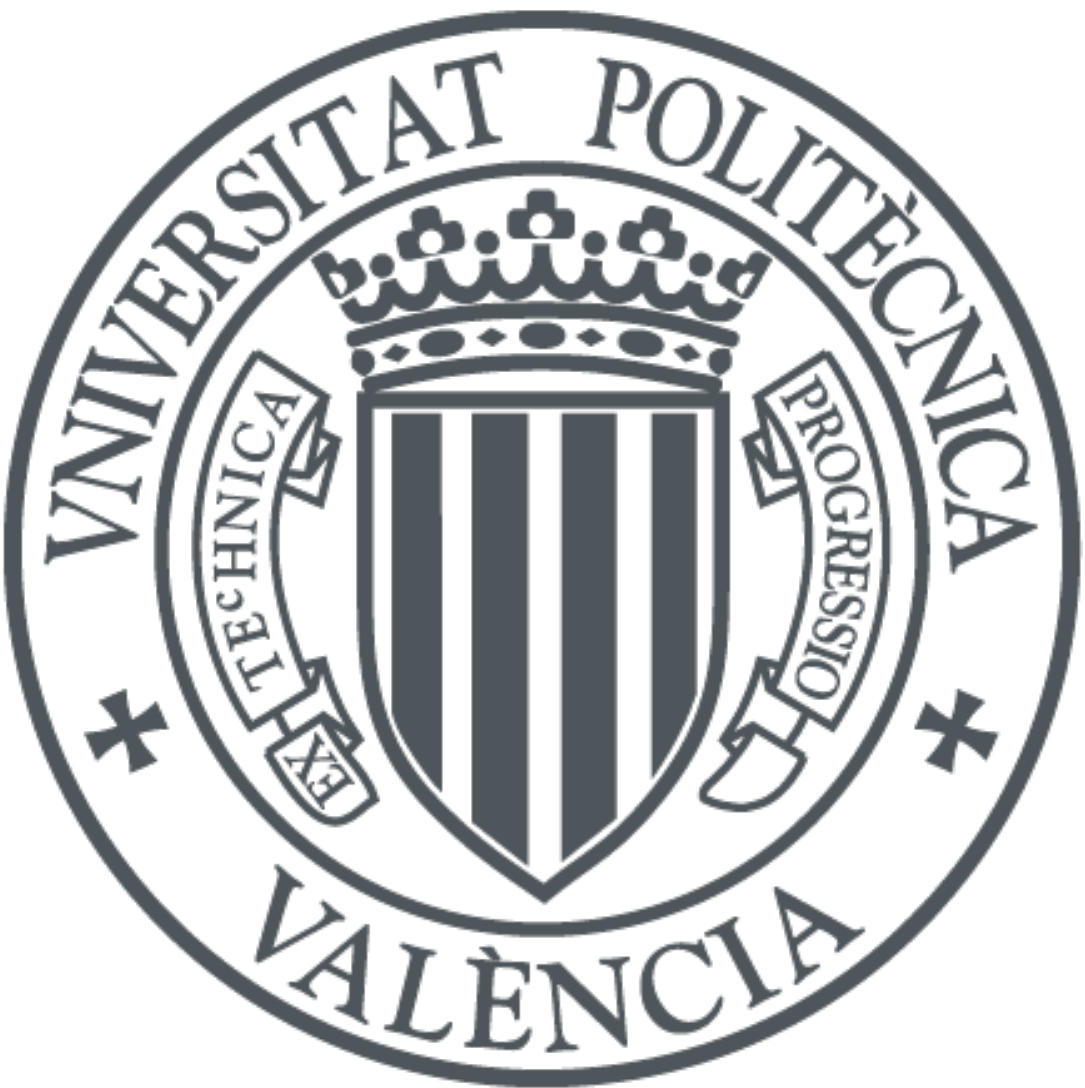

The final publication is available at

http://dx.doi.org/10.1177/0954409715626957

Copyright SAGE PUBLICATIONS LTD

Additional Information 


\title{
Methodology for evaluating thermal track buckling in dual gauge tracks with continuous welded rail
}

Authors: Ignacio Villalba Sanchis, Ricardo Insa Franco, Pablo Salvador Zuriaga and Pablo Martinez Fernandez

Affiliations: Department of Transport Engineering and Infrastructure, Universitat Politècnica de València, Spain

Corresponding Author: Ignacio Villalba Sanchis, Department of Transport Engineering and Infrastructure, Universidad Politécnica de Valencia, Camino de Vera, s/n, 46022 Valencia, Spain.

Email: igvilsan@cam.upv.es

\begin{abstract}
In the National Spanish railway network, two types of track gauge with continuous welded rails (CWR) are currently in use: the "Iberian” wide gauge (1668 mm) and the standard gauge (1435 mm). In order to improve links and freight traffic between different lines and with the rest of Europe, a dual gauge track with three rails was developed. This solution modifies the classical track configuration, so it is necessary to develop new methodologies and studies to understand its behavior. Among other loads
\end{abstract}


applied on a CWR track, a considerable rise in temperature induces compressive stresses in the three rails that can lead to lateral track buckling. Moreover, on dual gauge tracks the addition of the third rail increases the axial compression, which may lead to track instability. For this reason, a three-dimensional CWR model is developed in this study to be used for dual gauge track buckling analysis on straight tracks subjected to temperature load. The CWR dual gauge track model consists of beam and spring elements, in which a non-linear behaviour of the ballast is considered. The results obtained may be used to predict the buckling capacity of the CWR on dual gauge tracks with respect to different parameters such as lateral resistance, lateral imperfections, sleeper spacing or torsional stiffness.

\section{Keywords}

Track buckling; continuous welded rail; dual gauge; finite element model; nonlinear analysis; temperature; ballast resistance.

\section{Introduction}

The characteristic track gauge of the Spanish railway network is $1668 \mathrm{~mm}$ (measured between inner rail faces) wider than the standard track gauge of most European and world rail tracks, which is $1435 \mathrm{~mm}$. In order to improve links and freight traffic with the rest of Europe, in 1988 the Spanish Government decided to build dedicated high speed lines with standard track gauge. Furthermore, some important freight lines such 
as Mediterranean corridor will create a route over the $1300 \mathrm{~km}$ between French border and Algeciras.

The co-existence of different track gauges has been a problem for operators and passengers alike, due that trains cannot pass from a line with one track gauge to another with a different gauge. To solve interoperability issues, in the latest years some specific solutions have been tested and implemented. To allow the passage of trains from one network to another and run on both with minimum cost and construction times, a dual gauge track was developed, in which a third rail is added.

The addition of the third rail introduces an important modification of the traditional track system (see Figure 1), and thus requires an adequate and accurate analysis, especially in terms of track instability.

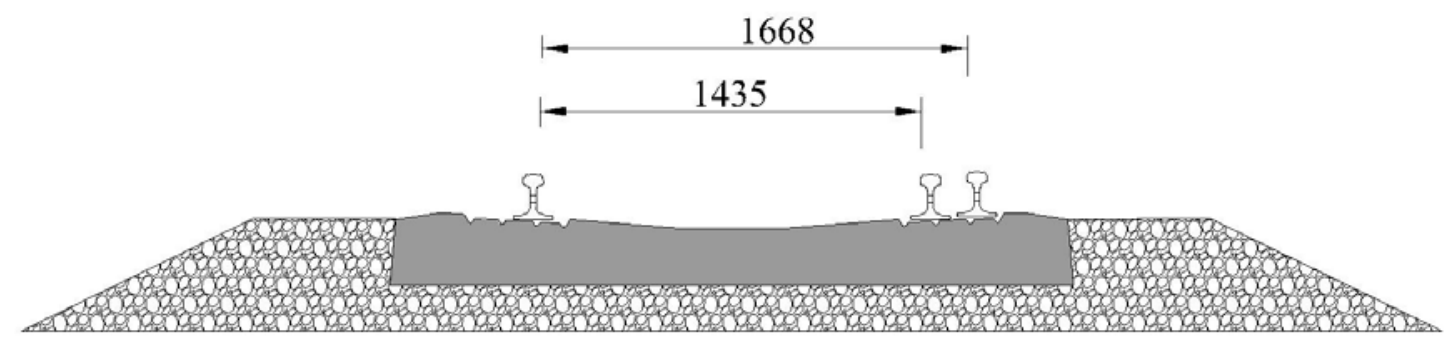

Figure 1. Schematic of dual gauge track section.

Considering the rail configuration, there are two types of systems. In conventional nonwelded tracks the rail ends are joined together mechanically with a gap between rails to 
make a continuous surface on which trains may run. Moreover, these joints allow the free expansion of the rails and decrease the axial compression forces due to temperature variations. On the other hand, these discontinuities between rails bring discomfort, increase track maintenance costs, power consumption, and noise.

In order to solve the problems associated to joints, modern railways introduced continuous welded rail (CWR) during the 1930s, in which the absence of joints offers several advantages such as savings in the cost of track maintenance, as well as the important gain in safety resulting from the elimination of rail joints (Tzepushelov ${ }^{1}$ ). However, due to the impossibility of expanding or contracting lengthwise, axial compressive stresses in the rails caused by an increase in temperature may lead to lateral track buckling, especially in the horizontal plane (see Figure 2).

Over the years, numerous studies have been performed on evaluating different aspects on CWR behaviour. According to the Volpe National Transportation Systems Center², lateral track buckling is a complex phenomenon in which many factors are involved and causes hundreds of derailments each year around the world. Although significant temperature increase in the rails can be dangerous, a good track design and maintenance prevents most accidents.

Several theoretical and experimental investigations have been carried out in the latest years. These studies frequently focus only on few factors, but the analysis of the 
instability on dual gauge tracks introduces new parameters which need to be taken into account, considering that the addition of one rail increases the axial compressions.

The objective of this study is to investigate the risk of buckling on dual gauge tracks with CWR. First, track buckling phenomenon is presented. Then, a dual gauge track buckling model is presented, wherein some important factors such as ballast lateral resistance, sleeper spacing, torsional stiffness and the amplitude of misalignment are considered. For this purpose, a 3-D nonlinear analysis using the finite elements method has been developed. Several conclusions have been derived, which is an important step in the study of the influence of different factors on the buckling process of dual gauge tracks.

\section{State of the art}

As previously mentioned, if the rail temperature becomes substantially higher than the stress-free rail temperature or rail neutral temperature, longitudinal forces can build up and accentuate the risk of track misalignment. Moreover, these longitudinal forces contribute to many problems such as rail joint failure, rail break or failure of turnouts, but the most important problem in terms of cost and safety is track buckling. The character of the axial forces is directly connected with the lateral stability of the track, so it is important to control the phenomenon. 
Normally, two different types of buckling can be considered: sudden bucking and progressive buckling (see Figure 2). Sudden buckling is ruled by two different critical temperatures, $T_{\max }$ and $T_{\min }$. When the $T_{\max }$ temperature is reached in the track, the force required will be zero and track will buckle explosively. After this first stage, the track may reach a stable state corresponding to the $\mathrm{T}_{\min }$ temperature. At that point, the track will buckle out after some external disturbance. Due that buckling can happen between these two temperatures, it is safe to expose the track to any temperature lower than Tmin, without risk of buckling. Normally, this type of buckling occurs under small radius curvature and lateral resistance of the ballast.

On the other hand, progressive buckling occurs when creep appears on track and lateral displacements increase progressively. When the critical temperature is reached $\left(T_{p}\right)$, track does not admit further energy and displacements increase significantly. Progressive buckling appears under large radius of curvature or in straight tracks with large lateral resistance. 


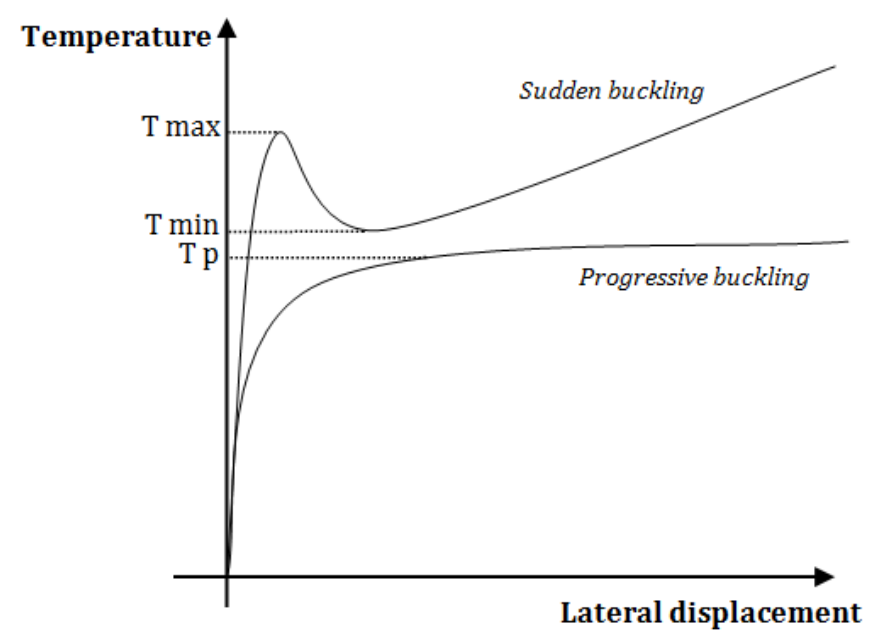

Figure 2. Different buckling responses.

Track buckling is influenced by different parameters which have their own individual effect, but often depend on other parameters. For this reason, correlations among different parameters need to be established. Different buckling theories were developed over the last 40 years. In 1964, Bijl ${ }^{4}$ developed a single beam model to analyze CWR track stability through energy methods. Meanwhile, Kerr ${ }^{5,6,7}$ develop theoretical analyses of track buckling and presented the concepts of the buckling region in which the track is unstable and has large deformations, but some effects such as the rotational stiffness of the fasteners, unsupported sleepers or maintenance effects on lateral resistance were not considered.

Kish et al. ${ }^{8,9,10}$. and Samavedam et al. ${ }^{11,12,13}$ published different articles using beam models to analyze track buckling behaviour. Their models incorporate track 
misalignments and nonlinearity of axial, lateral and torsional resistances of the track, but some factors such as uniform distribution of the ballast resistance, unsupported sleepers or different tracks gauges were not accounted for.

El-Ghazaly et al. ${ }^{14}$ established a three-dimensional 3-D finite element model of a single beam to analyze the track under static, deterministic loads. Only a bifurcation buckling load was studied, considering ballast resistance and fastener stiffness constant.

According to the European Railway Research Insitiute, in 1997 Van $^{15}$ uses a computer program CWERRI based on nonlinear finite element model, in which the stability of CWR on plain track and bridges can be calculated in three directions. The program results show that curvature, horizontal ballast strength and misalignment of the track are the most important parameters on CWR buckling analysis. A major application of CWERRI is its use as a tool for safety analyses.

From 1985 to 1988 Jackson et al. ${ }^{16}$ and Ramesh ${ }^{17}$ developed a finite element model with superelements including linear and nonlinear lateral deformation of the rail track under arbitrary thermal or mechanical loads. The model also considers torsional resistance of the fasteners and calculates post buckling deformations. However, it was a 2-D model in which vertical stiffness of the ballast and longitudinal stiffness of the padfastener were not considered. 
In 2006 López Pita ${ }^{18}$ presented a model based on the formulation of the equilibrium position of the deformed track. The model considers some different factors, such as the fasteners stiffness or a nonlinear behaviour of the ballast. However, the solution of the equations required many simplifications to be made and parameters such as misalignments of the track were ignored.

Recently, Lim et al. ${ }^{19,20}$ develop a model encoded into a special purpose program using the finite element method. The model considers the fastener stiffness, nonlinearity of the ballast resistance and track misalignments. The most important conclusion is that buckling of the track is a three-dimensional problem, and thus 2-D rail-tie models or beam models tend to overestimate the CWR track stability. In addition, the study concluded that $\mathrm{T}_{\max }$ depends on the lateral ballast resistance and the maximum amplitude of the imperfections and $\mathrm{T}_{\min }$ depends on the lateral and longitudinal ballast resistance.

In 2010, Choi et al. ${ }^{21}$ studied the buckling of a curved CWR track for lateral buckling prevention including thermal and vehicle loading effects in the evaluation of track stability. The model is based on static thermal buckling approach and shows that the upper critical buckling temperature $\mathrm{T}_{\max }$ is highly affected by the uplift due to vehicle loads. 
Considering dual gauge tracks, in 2008 Cuadrado et al. ${ }^{22}$ developed a three-dimensional finite element model to analyze the lateral buckling on dual gauge tracks. This model calculates the upper and lower buckling temperature on dual gauge tracks, considering train loads, radius of curvature and misalignments. The resolution must be done in two steps because the study comprises two sub-models: one to simulate the behaviour in the vertical plane and other to simulate the behaviour in the horizontal plane. The major limitation of this model is that the track structure is modeled as a single beam whose properties have been modified in order to represent the addition of the third rail. The unsymmetrical section represented by the addition of the third rail is not taken into account.

As pointed out above, most studies about track buckling consider only some different parameters that govern buckling phenomenon. In addition, due that a dual gauge track modifies substantially the conventional track structure, a more advanced threedimensional model for buckling analysis is urgently needed. The objective of this study is to analyze the lateral buckling phenomenon on Spanish dual gauge tracks through a new three-dimensional CWR track model.

\section{Development of three-dimensional track model}

The track buckling risk can be evaluated as a combination of different factors. Because the current models developed do not provide the possibility of incorporate a third rail 
and also because there is an absence of research regarding dual gauge tracks, an improved model has been developed using a three-dimensional finite element provided by ANSYS.

The finite element model represents a straight track in which some different elements are considered. The cross-section of the 3-D CWR track model is shown in Figure 3.
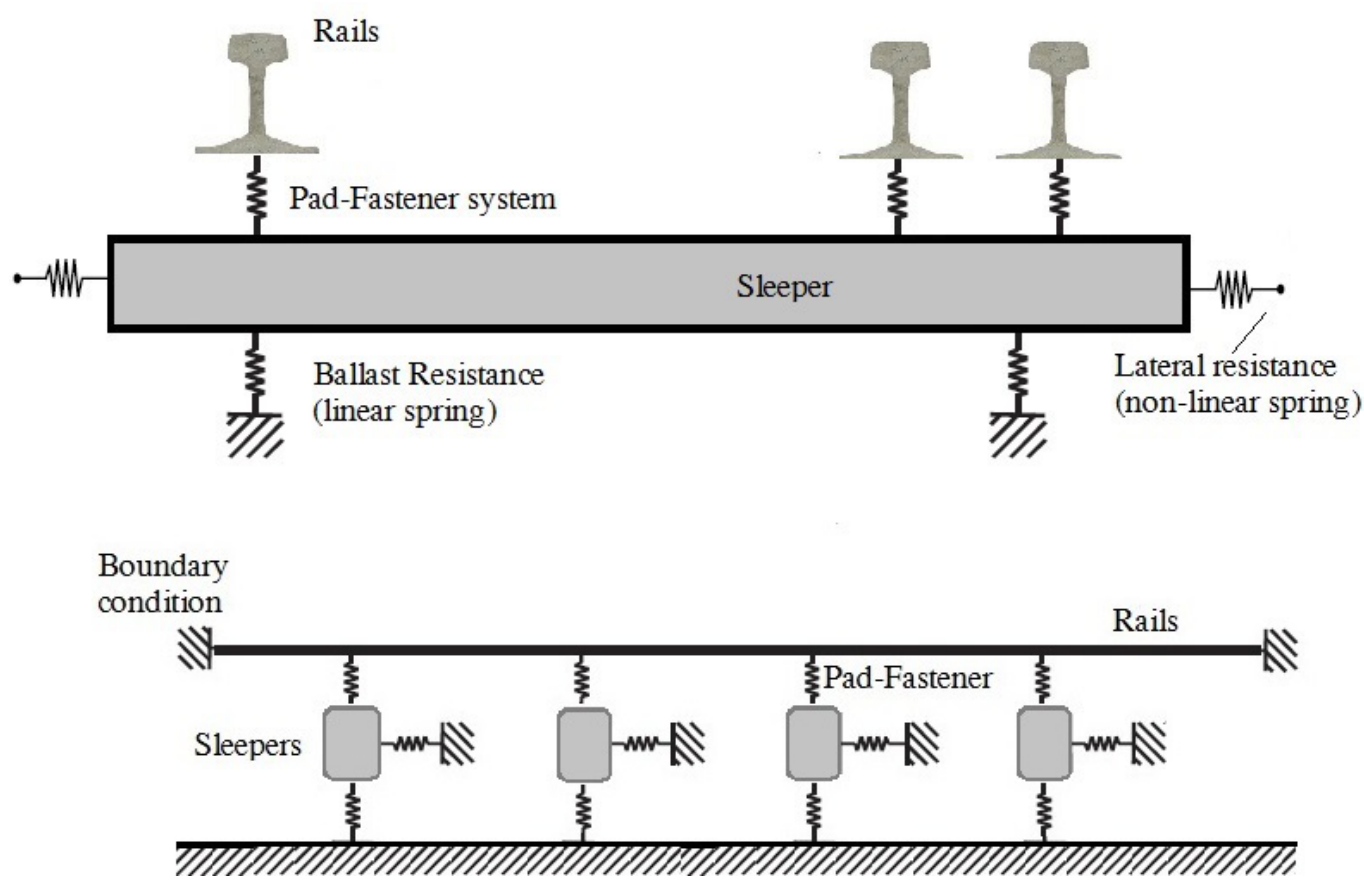

Figure 3. Cross section and side view of the model. 


\section{Model description}

The behaviour of a track structure is defined by the mechanical and geometrical properties of its elements. The proposed model considers the 3 rail track structure, which is a particular situation that occurs on Spanish railway network (see Figure 4).

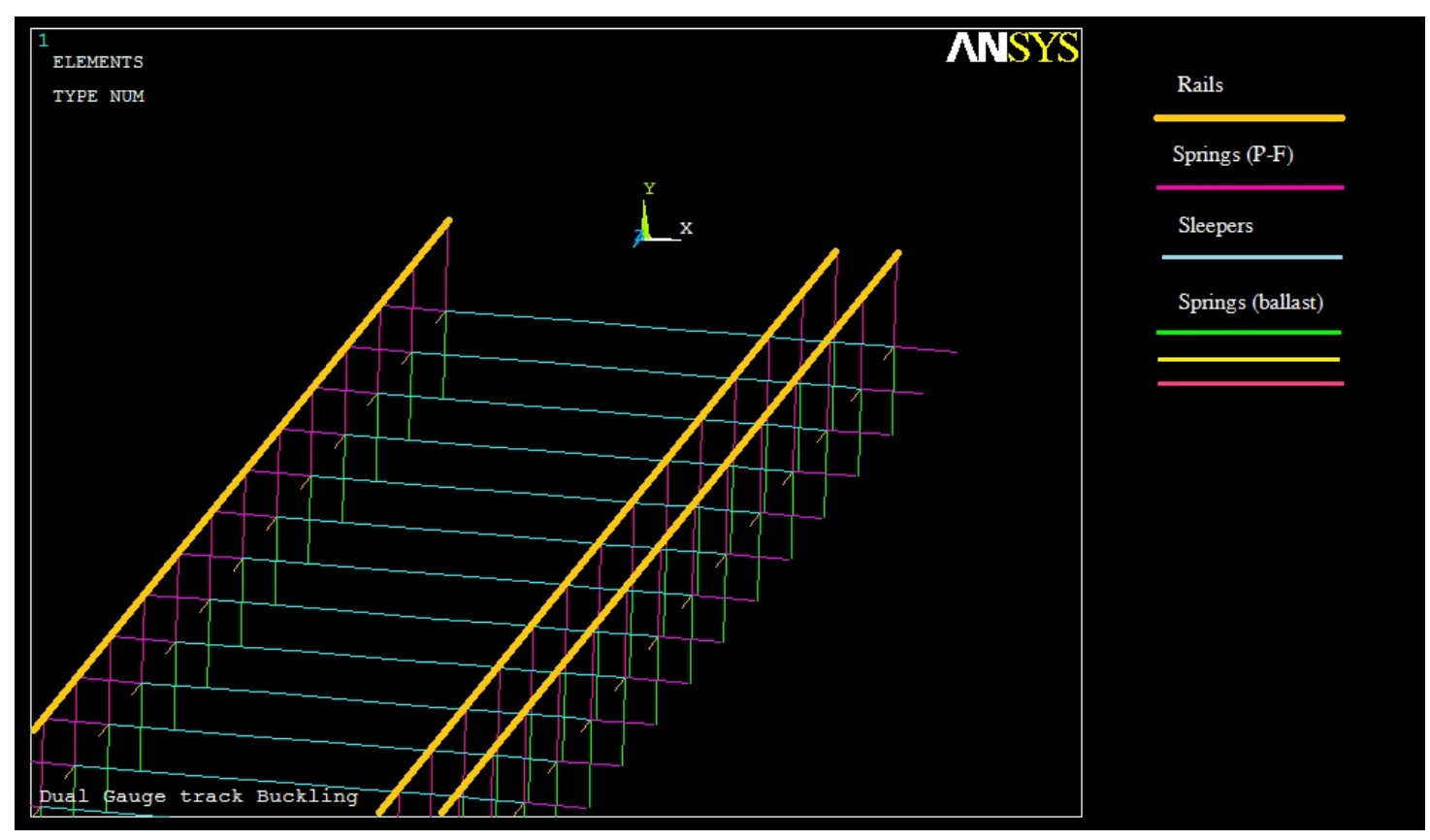

Figure 4. Ansys model view of three rail track.

Rails were modeled with 3-D beam elements with six degrees of freedom per node (including translations and rotations in the $\mathrm{x}, \mathrm{y}$ and $\mathrm{z}$ direction). The unit mass, young modulus and a coefficient of thermal expansion as well as a moment of inertia in vertical plane and the cross-section area were defined considering a UIC60 steel profile. The movements at the rail ends were fixed into the 3 directions, as it is assumed that the 
rails connected to them are properly constructed and therefore prevent displacement when the temperature increases.

The rails were joined to the sleepers thought the Pad-Fastener system, which was modelled as a set of linear spring elements using ANSYS commands in vertical, lateral and longitudinal directions. In addition, the rotational stiffness between the rail and the sleeper provided by the fasteners was simulated by an elastic rotational spring in the vertical direction. Therefore, each PF element consists of 4 springs, three for forcedisplacement and one for moment-rotation.

Sleepers were placed at fixed intervals along the length of the track, and the type considered was AM concrete sleeper (dual gauge sleeper), whose dimensions are 275x30x24 cm. The sleepers were represented as 3-D linear elastic beams specified by modulus of elasticity and cross-sectional area.

Finally, sleepers were supported by the ballast layer, whose modelization is very important to obtain a reliable buckling temperature. The resistance of the ballast layer depends on the type, weight, size, shapes and cross section dimensions of sleeper, the aggregation of ballast and maintenance operations.

On longitudinal and vertical directions the resistance was simulated with linear elastic springs. Considering the lateral resistance, according to Hunt et $a l^{23}$, Sussmann et $a l^{24}$, Zand et $a l^{25}$ and other previous research and experimental tests, it was assumed that the 
ballast lateral resistance behaviour is linearly elastic until a sleeper displacement $\mathrm{W}_{\mathrm{p}}$, when the resistance of ballast will not increase and remains at a constant level (see Figure 5).

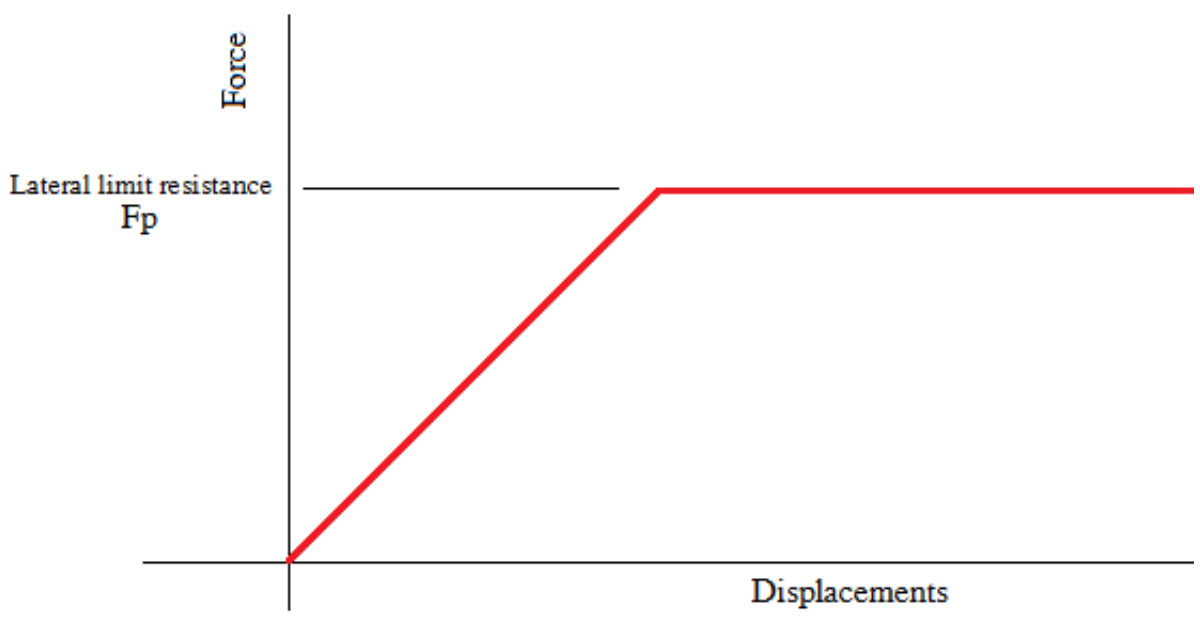

Figure 5. Non-linear spring behaviour.

To represent the ballast lateral resistance, a non-linear spring with elastic-plastic behaviour was considered, which means that the spring keeps resisting up to a lateral force $F_{p}$ that displaces the sleeper infinitely. However, when the sleepers are coupled with the rails between pad-fastener systems this infinite displacement is no longer possible, and the track reacts as established previously.

The main parameters are summarized in Table 1 and Table 2, based on the latest reports of European Railway Research Institute (ERRI) ${ }^{26}$. The geometry of the straight track section was defined by the length of the track. However, to determine the track length, 
different values were considered. The results show that a model with $60 \mathrm{~m}$ provides sufficient precision to perform the sensitivity analysis. In the CWR model, the necessary calculation time and computer memory depend on the type of track situation considered.

Table 1. Track model values of different parameters.

\begin{tabular}{cc}
\hline Parameters & Range of values \\
\hline Track length $(\mathrm{m})$ & 60 \\
Longitudinal ballast stiffness $(\mathrm{KN} / \mathrm{m})$ & 100 \\
Vertical ballast stiffness $(\mathrm{MN} / \mathrm{m})$ & $75-150$ \\
Rotational stiffness of the fasteners $(\mathrm{KNm} / \mathrm{rad})$ & $3000-9000$ \\
Lateral ballast peak resistance $\left(\mathrm{F}_{\mathrm{p}}\right)$, per sleeper $(\mathrm{KN})$ & $1-4$ \\
Amplitude of misalignments $(\mathrm{cm})$ & $50-70$ \\
Sleeper spacing $(\mathrm{cm})$ & 180 \\
Load per axle $(\mathrm{KN})$ &
\end{tabular}


Table 2. Rail and sleeper parameters.

\begin{tabular}{cccc}
\hline UIC 60 Rail section & Value & AM-05 sleeper & Value \\
\hline Section $\left(\mathrm{cm}^{2}\right)$ & 76.70 & Section $\left(\mathrm{cm}^{2}\right)$ & 655 \\
Young Modulus (GPa) & 210 & Young Modulus & 30 \\
Shear Modulus (GPa) & 81 & Shear Modulus & 12.70 \\
Inertia Moment $\mathrm{I}_{\mathrm{y}}$ & 3038.3 & & \\
Inertia Moment $\mathrm{I}_{\mathrm{z}}\left(\mathrm{cm}^{4}\right)$ & 512.3 & & \\
Expansion coefficient & $12 \mathrm{e}-6$ &
\end{tabular}

\section{Buckling study}

Parametric analysis

A parametric study was performed in order to evaluate the effects of the different parameters on the critical track buckling temperature. The parameters considered were: lateral resistance, torsional stiffness, sleeper spacing, initial misalignment amplitude and track load. Each parameter was varied within a practical range while the other parameters were fixed.

In order to calculate the buckled temperatures, two different analyses were performed. Firstly, because some perturbation is necessary to trigger the buckling phenomenon, an initial misalignment of $1 \mathrm{~cm}$ was introduced in the central node of the model. 
After that, the track was loaded with a temperature (neutral temperature of $25^{\circ} \mathrm{C}$ was established) obtaining the temperature-lateral displacement curves at the central point of the track until the buckling is reached.

Model resolution provides not only the buckling temperature, but also the amplitude of the deformation. Due that the deformed shape is related to the initial misalignment introduced, the buckled shape obtained from the model is shown in Figure 6. Therefore for each value of initial misalignment a value of temperature is given.

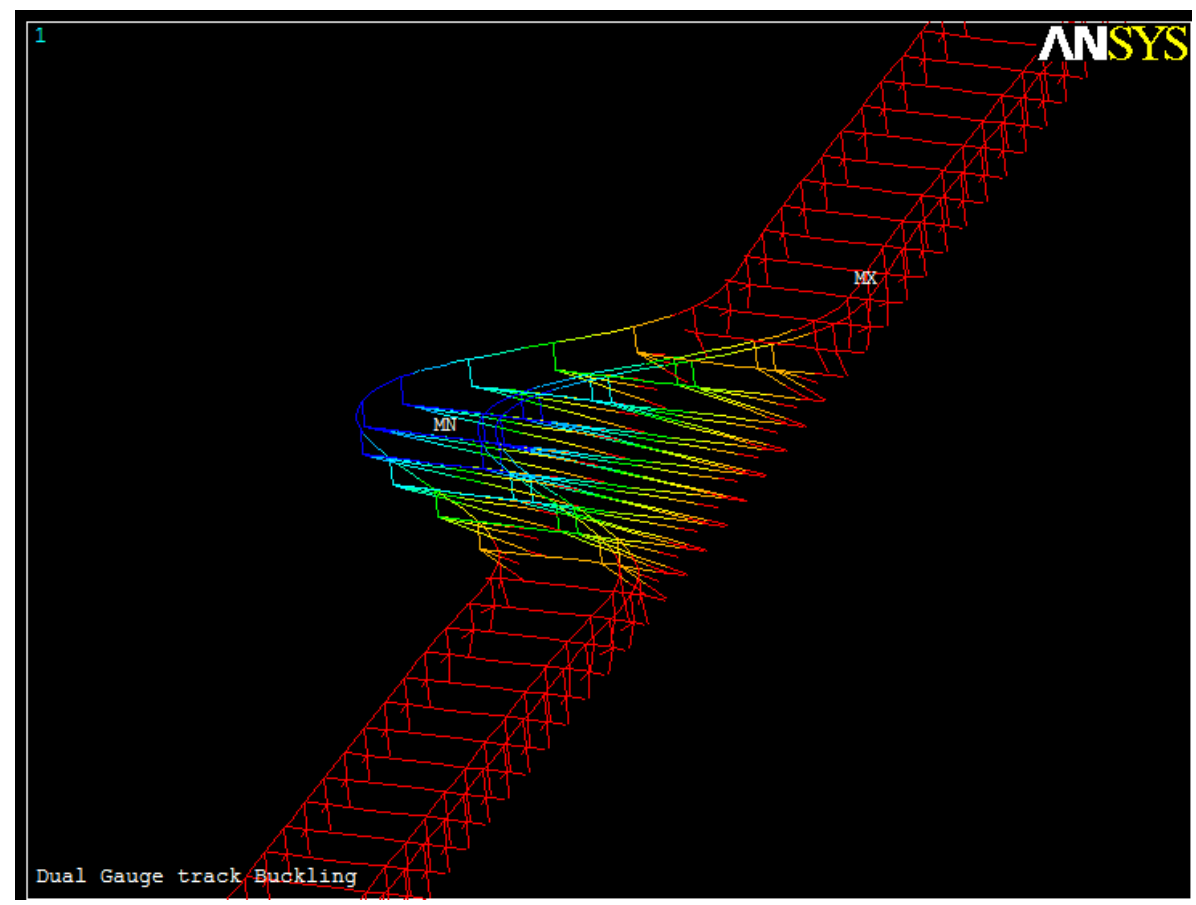

Figure 6. View of the track buckled shape. 
In order to carry out an in-depth study on the influence of the different factors, temperature-parameter curves at the central node were obtained.

As discussed previously, lateral resistance has a large influence on track buckling. Figure 7 represents the influence of the ballast lateral resistance on the buckling temperature, which was varied over a range of $50 \%$ to $150 \%$ of the reference value (7000 KN per sleeper). The result indicates that varying the ballast lateral resistance has more influence on buckling temperature than other parameters studied. As such, track lateral resistance becomes a fundamental and yet highly variable parameter, as it is affected by many track conditions such as ballast section, consolidation, and maintenance operations.

In order to analyze the effect of misalignments in the track, different amplitudes were considered. Figure 8 shows the effect of misalignment amplitude on buckling temperature. Buckling starts at lower temperatures when the amplitude of misalignment reaches values over $3 \mathrm{~cm}$. In addition, for an unloaded track, the buckling temperature for $1 \mathrm{~cm}$ amplitude is about $50 \%$ higher than for the $4 \mathrm{~cm}$ amplitude.

As can be seen in Figure 8, this behaviour is similar when the track is loaded. However, when a vertical load is applied on track, the buckling temperatures are over $30 \%$ higher than for unloaded tracks for the same misalignment. According to $\mathrm{Kish}^{27}$ and other 
researchers, this effect is due to vertical loads tending to increase the lateral resistance and friction coefficient exerted by the ballast layer.

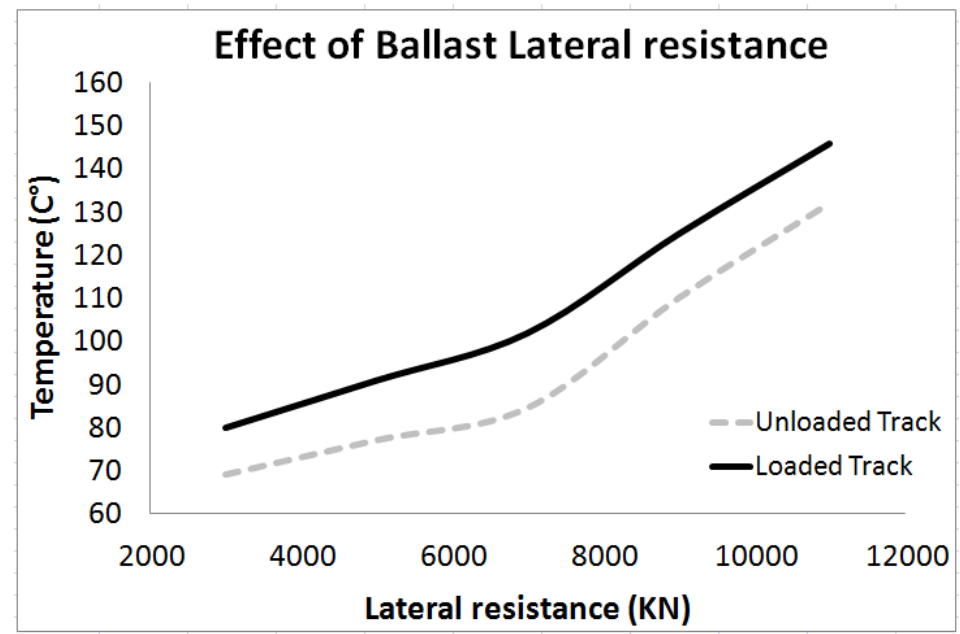

Figure 7. Temperature-Lateral resistance curve

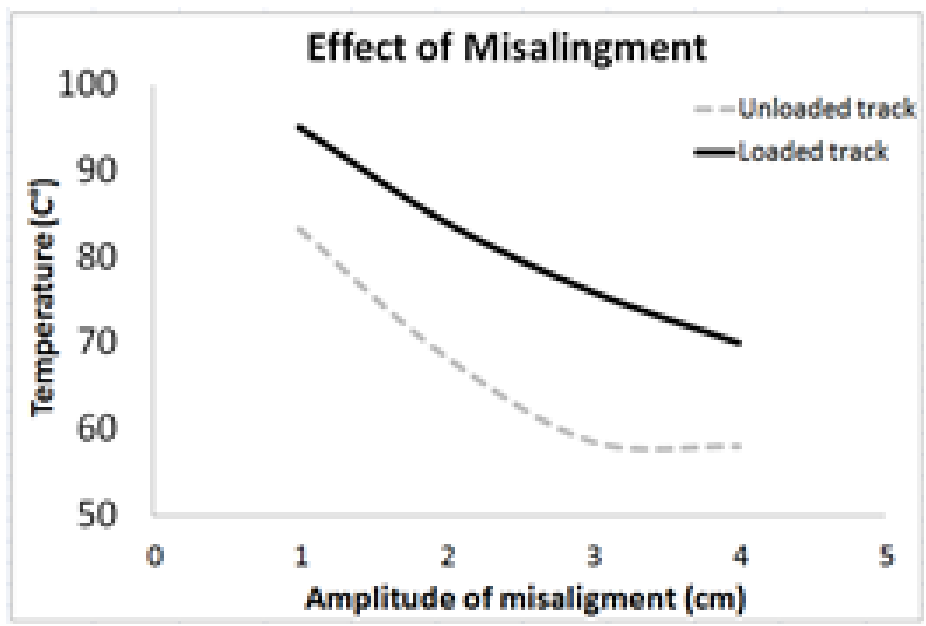

Figure 8. Temperature-Misalignment curve 


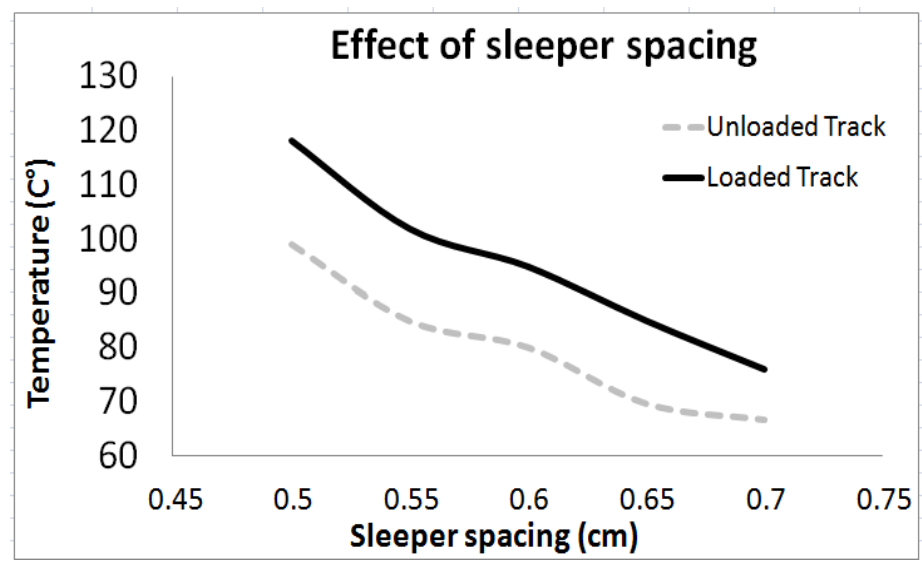

Figure 9. Temperature-Sleeper spacing curve

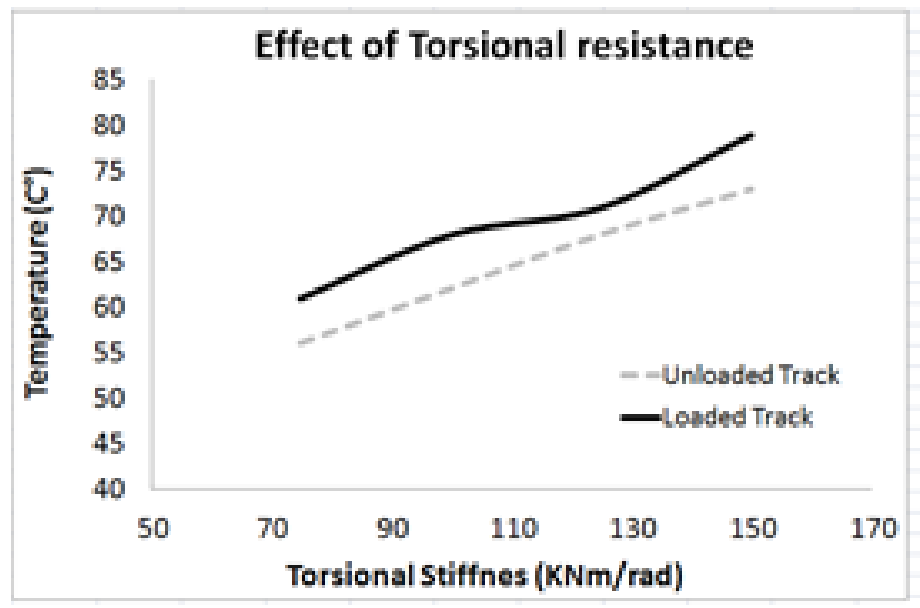

Figure 10. Temperature-Torsional stiffness curve

The effects of sleeper spacing on the CWR dual gauge tracks are examined considering a range of values from 0.5 to $0.7 \mathrm{~m}$. The buckling results are shown in Figure 9. The buckling temperatures follow the same trends with increasing sleeper spacing. However, the lower values of temperature correspond to maximum values of sleeper spacing. 
Figure 10 shows the influence of the torsional stiffness resistance. The effect of the fasteners increases the lateral stability of the track structure because large values of rotational resistance rely much more on the lateral stability to resist lateral track movement.

Figure 11 displays the buckling temperature for the different parameters and its different values considered, when the track is unloaded. As the Figure 11 shows, the lateral resistance is the most important parameter regarding track lateral stability on dual gauge tracks. Therefore, variation of the other factors has only a minor effect on the global rigidity of a dual gauge track. In addition, lower lateral resistance and torsional stiffness values may easily reduce buckled temperature (around $60^{\circ} \mathrm{C}$ ) that may cause track instability. 


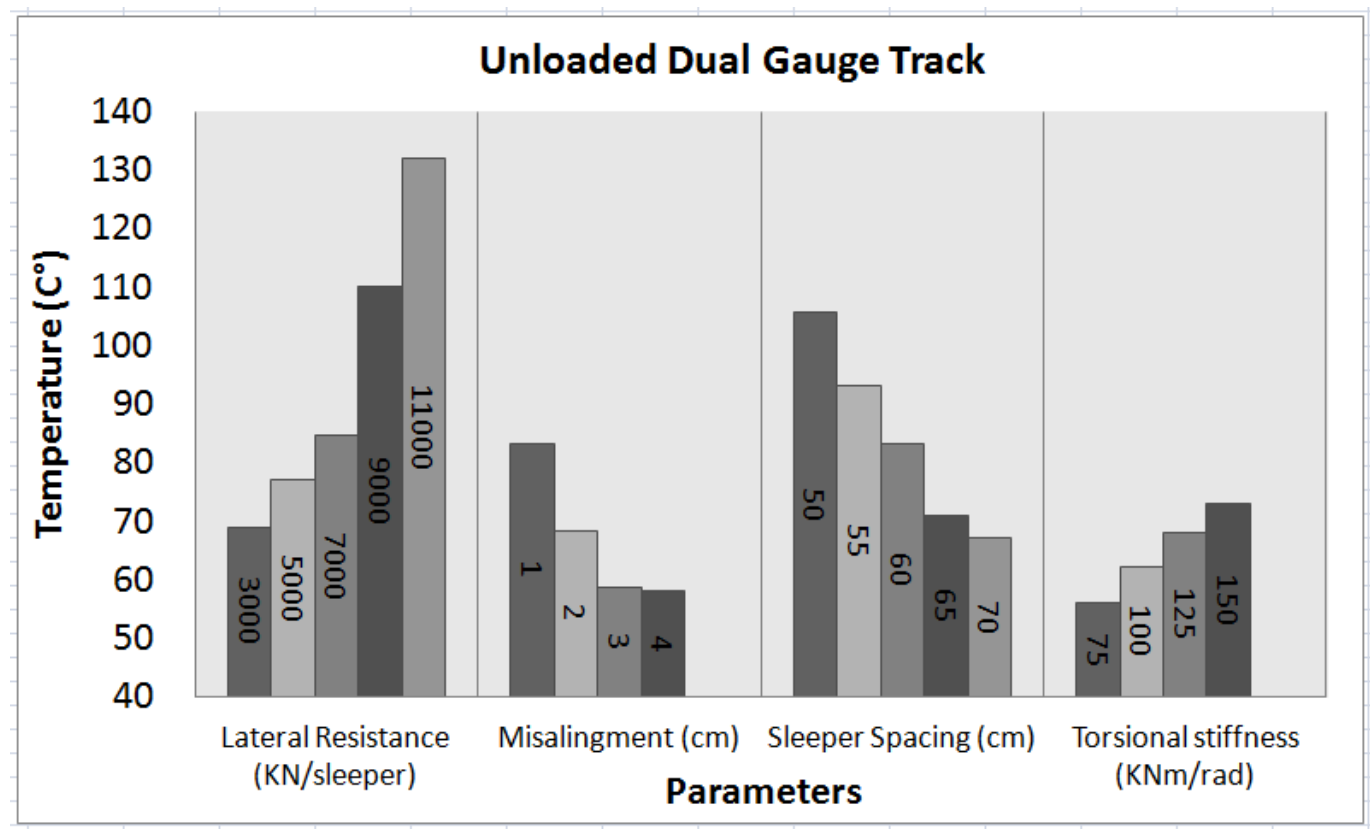

Figure 11. Buckled temperatures for different parameters.

It should be noted that track buckling is influenced by train loads and the energy transmitted. In addition, train loads are not only caused by the weight of the vehicle itself but also by dynamic loads in longitudinal and lateral directions originated during train passage. Thus, when a vertical load is applied on the track, the increase in its stability is mainly due to the base resistance of the ballast.

For reduced speeds, train loads increase the lateral stability and the track buckling temperature, in line with the results presented above. On the other hand, high speeds may induce a reduction of lateral resistance caused by track uplift and energy 
transmitted, so the temperature of buckling will decrease. However, for simplicity, this effect is not taken into account in the analysis.

Comparative study between conventional and dual gauge tracks

Based on the finite element model described above, a comparative study with a conventional railway track was performed. The parameters used for the conventional track are equal to those used in table 2 and 3 except for sleeper, whose mechanical properties correspond to a 2-rail sleeper.

The parameters considered are lateral resistance, amplitude of misalignment and torsional stiffness. Results from comparisons of dual gauge tracks and conventional tracks when track was unloaded are shown on Figure 12. 


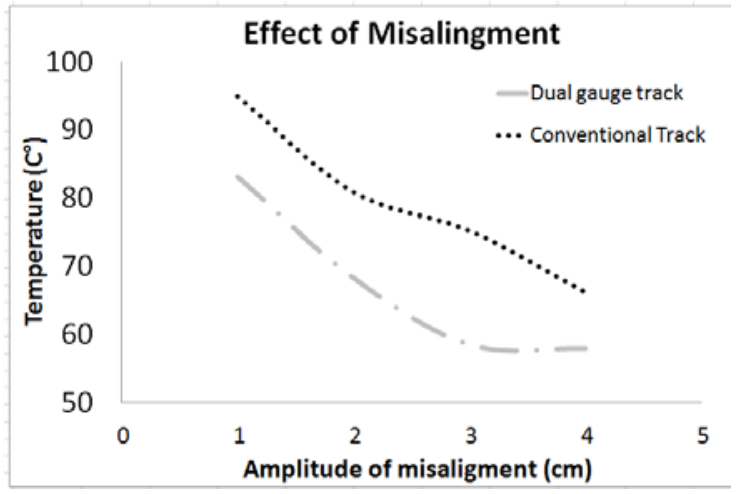

a)

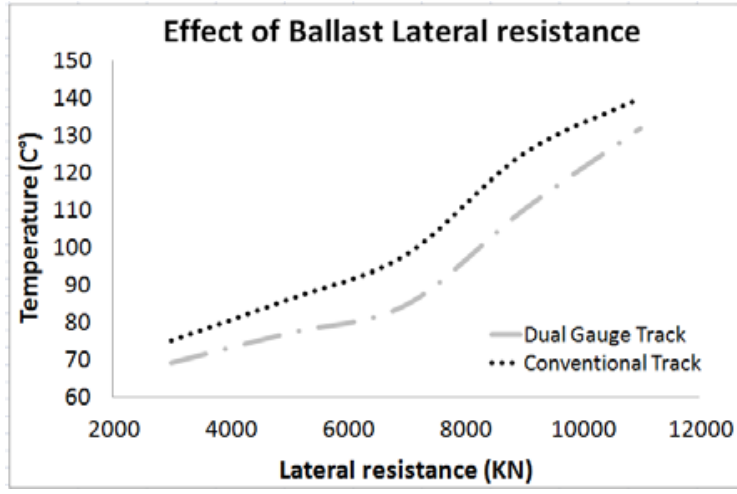

b)

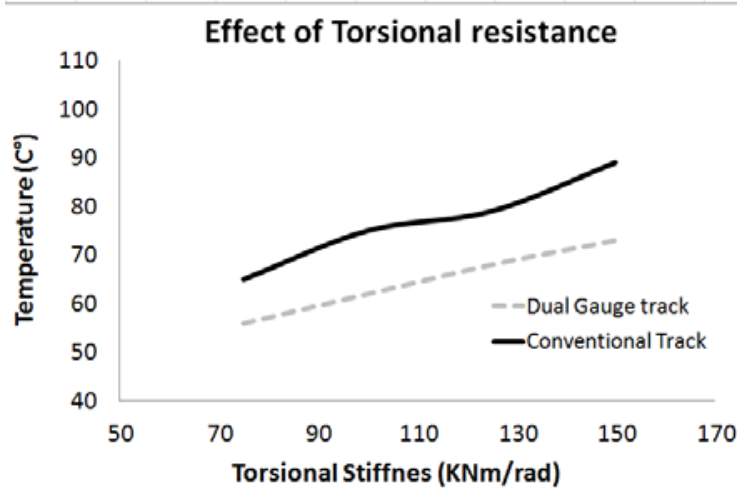

c)

Figure 12. Different Temperature-Factor curves for dual and conventional tracks. a)

Effect of misalignment, b) Effect of ballast lateral resistance, c) effect of torsional resistance. 
From the comparison, it should be noted that the shape of the temperature-displacement curve at the central node in both tracks are similar. The results obtained shows also the effect of the considered misalignment on the value of the track buckling temperature. It can be seen that for dual gauge tracks, the buckling load for different misalignment values is around $12 \%$ higher than for conventional tracks. This is a consequence of the high stress level in the horizontal plane of the 3-rail tracks

In addition, the results obtained on dual gauge tracks shows that a mean buckling temperature that is $10 \%$ lower than the buckling temperature for a conventional track. This confirms the importance of correct design and maintenance operations, especially on dual gauge tracks.

Moreover, the buckling temperature for a track with three rails is approximately $5^{\circ} \mathrm{C}$ to $15^{\circ} \mathrm{C}$ lower than the buckling temperature for a conventional track. This is due to the fact that lateral stability on dual gauge tracks do not increase in the same proportion as compressive forces in central part (buckled zones) and the total stability of the dual gauge track is reduced. Therefore, the risk of buckling is far greater on dual gauge tracks.

\section{Conclusions}

In this paper, the thermal buckling of dual gauge tracks in the lateral plane was analyzed with a three-dimensional finite element model. The main contributions of this model are 
that it allows the calculation of the buckling load of a dual gauge tracks, considering the effects of lateral resistance of the ballast, torsional resistance, track misalignment and the effect of sleeper spacing.

The CWR track model consists of geometrical beams representing the rails and sleepers, which are connected with linear elastic springs. The longitudinal resistance of the sleepers is modeled with elastic springs, while the lateral resistance is modeled with elastoplastic springs.

To predict the buckled temperature, an initial misalignment was considered, obtaining the results in terms of the temperature of the rails above the neutral temperature. Furthermore, the effect of the lift-up wave of the loaded track was considered by applying train loads.

In order to analyze the influence of different parameters, a parametric study was performed. The results obtained show that lateral resistance and initial misalignment are key parameters for lateral track stability. Furthermore, the sleeper spacing has a great influence on the buckled temperature compared with torsional stiffness. In addition, in all cases the risk of buckling is higher when the track is unloaded, because of the increase of ballast lateral resistance due to vertical loads.

In addition, a comparison between conventional and dual gauge tracks was performed. The results reveal that the acceptable increase of temperature on dual gauge tracks is 
$5^{\circ} \mathrm{C}$ to $15^{\circ} \mathrm{C}$ lower than conventional tracks. Therefore, this type of track requires special attention and more accurate maintenance operations so as to reduce the risk of buckling and increase the safety margin.

The model was applied to a straight CWR track subjected to thermal and trains loads. However, it can be expanded to include more complex situations by considering the track structure with two or three rails, including track curvature, heterogeneous ballast resistance and different types of imperfections. Finally, some correlations among different parameters need to be established to provide better maintenance and inspection procedures on dual gauge tracks. 


\section{References}

1. Tzepushelov A. Troyitzky L. Design, laying, maintenance and repair of continuously welded rails on the USSR railways. Rail Int 4, 1974, pp. 589-605.

2. Volpe National Transportation Systems Center, Track Buckling Research, Research and Innovative Technology Administration — U.S. Department of Transportation, Washington, 2003.

3. Railway investigation: Main-track derailment. Canadian national freight train a435-31-14. Mile 6.0, Oakville subdivision mimico, Ontario 14 july 2006, Report r06t0153, 2006, Transportation Safety Board of Canada (TSB), Canada.

4. Bijl, F. Buckling force in gapless track calculated in a nonlinear manner, De Ingenieur, 1964, pp. 119-123.

5. Kerr A. D. The effects of lateral resistance on track buckling. Rail Int. 1, 1976, pp. 30-38.

6. Kerr A. D. Analysis of thermal track buckling in lateral plane, Acta Mech. 30, 1978, pp. 17_50

7. Kerr A. D. and El-Aini Y. M. Determination of admissible temperature increases to prevent vertical track bruckling, J. Appl. Mech. 45, 1978, pp. 565-573.

8. Kish A. Samavedam G. and Jeong D. Analysis of thermal buckling tests on U.S. railroads, FRA/ORD82/45, 1982, Washington D.C., USA. 
9. Kish A. Samavedam G. and Jeong D. Influence of vehicle induced loads on the lateral stability of CWR track. DOT/ FRA/ORD-85/03, 1985, Washington, DC., USA.

10. Kish A. and Samavedam G. Dynamic Buckling of Continuous Welded Rail Track: Theory, Tests, and Safety Concepts. TRB’s 1289, 1991, pp. 23-38.

11. Samavedam G. Buckling and post buckling analysis of CWR in the lateral plane, British Railways Board, Technical Note TNTS-34, 1979.

12. Samavedam G. Kish A. and Jeong D. Parametric studies on lateral stability of welded rail track. DOT/FRA/ORD-83/ 07, 1983, Washington, DC., USA.

13. Samavedam G. Kish A. Purple A. and Schoengart J. Parametric studies on lateral stability of welded rail track, DOT/FRA/ORD-93/26, 1993, Washington, D.C., USA.

14. El-Ghazaly H. A. Sherbourne A. N. and Arbabi F. Strength and stability of railway tracks - II. Deterministic, finite-element stability analysis, Comput. Struct. 39, 1991 pp. 23-45.

15. Van M. A. Stability of continuous welded rail track, PhD thesis, Delft University of Technology, Delft, 1997.

16. Jackson J. E. Bauld N.R. Ramesh M.S. and Menon S.C. A super element for lateral track deformation, in Proc. of Applied Mechanics Rail Transportation Symp. ASME’s, Chicago, IL, 1988, pp. 7-18. 
17. Ramesh M. S. A Nonlinear Finite Element Approach to the Analysis of Lateral Thermal and Mechanical Buckling of Railroad Tracks, Clemson University, USA, 1985.

18. López Pita A. Infraestructuras ferroviarias. (Ediciones UPC, 2006, in spanish).

19. Lim N. H. Park N. H. and Kang Y. J. Stability of continuous welded rail track, Comput. Struct. 81, 2003, pp. 2219-2236.

20. Lim N. H. Han S.Y. Han T.H. and Kang Y.J. Parametric Study on Stability of Continuous Welded Rail Track -Ballast Resistance and Track Irregularity- Steel Struct. 8, Vol 8 No.3, 2008, pp. 171-181.

21. Choi D.H. and Na H.S. Parametric Study of Thermal Stability on Continuous Welded Rail. IJR Vol. 3, No. 4, 2010, pp. 126-133.

22. Cuadrado M. Zamorano C. González P. Nasarre J. and Romo E. Analysis of bucklinf in dual gauge tracks, Proceedings of The Institution of Civil Engineerstransport - Proc inst civil eng-transport, vol. 161, 2008, no. 4, pp. 177-184.

23. Hunt D. and Yu Z. Measurement of Lateral Resistance Characteristics for Ballasted Tracks, ERRI D 202/DT 361 Report, 1998, Utrecht, Netherlands.

24. Sussmann T. Kish A. Trosino M. Investigation of the Influence of Track Maintenance on the Lateral Resistance of Concrete Tie Track, TRB’s Conference, 2003. 
25. Zand J. and Moraal J. Ballast Resistance under Three Dimensional Loading. Report 7-97-103-4, 1997, Roads and Railways Research Laboratory, TU Delft.

26. ERRI Specialists' Committee D 202, Improved knowledge of forces in CWR track, ERRI. D 202/RP 11, ERRI, Utrecht, 1999.

27. Kish A. On the Fundamentals of Track Lateral Resistance, American Railway Engineering and Maintenance of Way Association, 2011. 